УДК 620.9:504

В. П. Кравченко, С. В. Кравченко

Одеський національний політехнічний університет, пр. Шевченка, 1, м. Одеса, 65044, Україна

\title{
УДОСКОНАЛЕННЯ МЕТОДИКИ ВИЗНАЧЕННЯ ЕКОЛОГІЧНОЇ СКЛАДОВОЇ В ТЕХНІКО- ЕКОНОМІЧНИХ РОЗРАХУНКАХ ЕНЕРГЕТИЧНИХ УСТАНОВОК
}

Запропоновано при розрахунку екологічної складової приведених витрат ставку податку за викиди вуглецевого газу рахувати як суму ставки за Податковим кодексом Украйни та ставки за Кіотським протоколом. Одною з переваг сонячної, вітрової та атомної енергетики є відсутність використання кисню. Запропоновано при співставленні енергоустановок враховувати плату за вживання кисню. Запропоновано методику визначення ставки изього податку. Розраховано приведені витрати для котла на природному газі та сонячної установки.

Ключові слова: Річні приведені витрати; Екологічна складова експлуатачійних витрат; Плата за використання кисню.

\section{В. П. Кравченко, Е. В. Кравченко}

Одесский национальный политехнический университет, пр. Шевченко, 1, г. Одесса, 65044, Украина

\section{МЕТОДИКА ОПРЕДЕЛЕНИЯ ЭКОЛОГИЧЕСКОЙ СОСТАВЛЯЮЩЕЙ В ТЕХНИКО- ЭКОНОМИЧЕСКИХ РАСЧЕТАХ ЭНЕРГЕТИЧЕСКИХ УСТАНОВОК}

Предложено при расчетах экологической составляющей ставку налога за выбросы углекислого газа считать как сумму ставки по Налоговому кодексу Украины и ставки по Киотскому протоколу. Одним из преимуществ солнечной, ветровой и атомной энергетики является отсутствие использования кислорода. Предложено при сопоставлении разных энергоустановок учитывать плату за потребление кислорода. Предложена методика определения ставки этого налога. Рассчитаны приведенные затраты для котла на природном газе и солнечной установки.

Ключевые слова: Годовые приведенные затраты; Экологическая составляющая эксплуатационных затрат; Плата за потребление кислорода.

This work is licensed under the Creative Commons Attribution International License (CC BY). http://creativecommons.org/licenses/by/4.0/

\section{I. ВСТУП}

При розробці любих проектів, у тому числі для використання альтернативних джерел енергії, завжди треба робити техніко-економічне обгрунтування. Зараз ці розрахунки показують низьку привабливість використання альтернативних джерел енергії. Це визначається високими капіталовкладеннями та відносно низькими цінами на традиційне паливо. Основною перевагою альтернативних джерел є низький вплив на навколишнє середовище, тому для підвищення привабливості цих енергоджерел треба більш ретельно враховувати екологічну складову витрат при розрахунку економічних показників традиційних енергоустановок.

Метою роботи є удосконалення методики техніко-економічного співставлення енергоустановок 3 урахуванням екологічної складової експлуатаційних витрат.

\section{II. МЕТОДИКА СПІВСТАВЛЕННЯ ЕНЕРГОУС- ТАНОВОК}

Одним 3 узагальнених критеріїв технікоекономічної оптимізації енергетичних установок та критерієм економічної ефективності природокористування $є$ мінімум приведених витрат $[1,2]$ :

$$
3=\mathrm{E}_{\mathrm{H}} \cdot К+И,
$$

де $\mathrm{E}_{\mathrm{H}}$ - нормативний коефіцієнт ефективності капітальних вкладень, який дорівнює 0,12 для нових об'єктів та 0,15 - для модернізації. Для спорудження унікальних експериментальних об'єктів величин

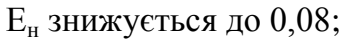

К- капіталовкладення;

И - поточні річні виробничі витрати в розглянутій установці, які складаються 3 витрат на паливо, складової капітальних витрат та експлуатаційних витрат

$$
И=И_{\text {п }}+И_{\kappa}+И_{\text {експ }},
$$

де $И_{\text {п }}$ - витрати на паливо.

Складова капітальних витрат визначається як

$$
И_{\mathrm{K}}=\mathrm{p}_{\mathrm{a}} \cdot \mathrm{K}+И_{\text {т.в. }},
$$

де $\mathrm{p}_{\mathrm{a}} \cdot \mathrm{K}$ - амортизаційні відрахування;

$\mathrm{p}_{\mathrm{a}}$ - коефіцієнт амортизації, що враховує відрахування на реновацію та капітальний ремонт та залежить від виду устаткування та режиму його роботи; 
$И_{\text {т.в. }}$ - річні витрати на поточний ремонт, які приймаються в розмірі 10-20 \% від амортизаційних відрахувань.

Коефіцієнт $\mathrm{p}_{\mathrm{a}}$ відповідно нормам, прийнятим у 80-і роки, виражався у \% від початкової вартості і складав у цілому для енергоустановки для приблизних розрахунків 6-8 \% в залежності від якості палива та числа часів використання встановленої потужності.

Експлуатаційні витрати визначаються, як

$$
И_{\text {експ }}=И_{\text {зп }}+И_{\text {пр }}+И_{\text {екол }},
$$

де $И_{3 п}$ річна зарплатня персоналу;

$И_{\text {пр }}$ - інші загальні витрати;

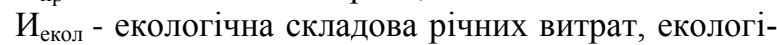
чний податок.

\section{III. МЕТОДИКА ВИЗНАЧЕННЯ ЕКОЛОГІЧНОЇ СКЛАДОВОЇ РІЧНИХ ВИТРАТ}

Пропонується в екологічному податку враховувати плату за використання кисню, що $є$ одною 3 переваг альтернативних джерел енергії. В цьому випадку екологічна складова визначиться за формулою [3]:

$$
И_{\text {екол }}=\Pi_{\text {кн }}+\Pi_{\text {вик }}+\Pi_{\text {очищ }},
$$

де $\Pi_{\text {кн }}-$ плата за користування надрами [4];

$\Pi_{\text {вик }}$ - плата за викиди;

$\Pi_{\text {очищ }}-$ плата за очищення;

$\Pi_{\text {кис }}$ плата за використання кисню.

Зі смислу податку за користування надрами виходить, що він входить у вартість сировини чи палива i для енергетичних установок окремо не використовується.

Сума податку, який сплачується за викиди в навколишнє середовище забруднюючих речовин стаціонарними джерелами забруднення, обчислюється, виходячи з фактичних обсягів викидів та ставок податку за формулою:

$$
\Pi_{\text {вик }}=\sum_{\mathrm{i}=1} \mathrm{M}_{\mathrm{i}} \cdot \mathrm{H}_{\text {пі }}
$$

де $\Pi_{\text {вик }}-$ сума податку, грн;

$\mathrm{M}_{\mathrm{i}}$ - обсяг викиду і-ої забруднюючої речовини, т;

$\mathrm{H}_{\text {пі }}$ - ставка податку за викид і-ої забруднюючої речовини, грн/т.

Як представляється, плата за викиди може бути зменшена, якщо використовувати засоби очищення,

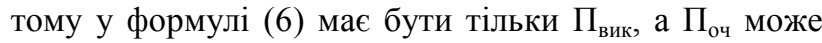
бути видалене.

Під економічним збитком, завданим навколишньому середовищу, розуміють виражені в вартісній формі фактичні або можливі втрати, заподіяні господарству, суспільству, чи додаткові витрати на компенсацію цієї шкоди [2].

Для порівнянності варіантів вони повинні приводитися до однакового рівня шкідливого впливу на довкілля або слід враховувати додаткові витрати для здійснення заходів щодо захисту навколишнього середовища.
Особливу увагу зараз приділяють викидам парникових газів, головним 3 яких $є$ двоокис вуглецю. При розгляді таких нетрадиційних джерел енергії як сонце, вітер, атомна енергетика завжди серед їх переваг відмічається невикористання кисню [5]. Тобто використання кисню у традиційній енергетиці є важливим недоліком, оскільки кисень - це найважливіший компонент забезпечення життєдіяльності всього живого на Землі.

Треба відмітити, що використання кисню сьогодні не регламентується. В роботі пропонується при співставленні різних енергоустановок враховувати використання кисню. Виходячи 3 наведених матеріалів, платіж за використання кисню має бути еквівалентом відновлення його витраченої кількості. Тобто за найбільш доступною технологією [6].

Промисловість виробляє кисень 3 повітря. Якщо виробляти кисень 3 повітря, це не буде його відновленням. У повітрі кисень знаходиться у корисній формі. Тому треба розглядати технологію виробництва кисню $з$ вуглецевого газу. Таким процесом $є$ фотосинтез. Виробництво кисню з $\mathrm{CO}_{2}$ у промисловому виробництві не застосовується. Таким чином приймаємо, що виробництво кисню лісом є найбільш доступною технологією.

Кількість виділеного і поглиненого кисню одним і тим же деревом залежить від пори року і може змінюватися від нуля до максимального значення в середньому за добу. Динаміка виділення/поглинання кисню змінюється від одного виду рослини до іншої. Від пори року так само залежить відношення кількості поглиненого кисню до кількості виділеного в середньому за добу.

Відповідно даним [7] з одного гектару соснових насаджень за один рік виділяється 10,9 т, березових 10,8 т, осикових - 9,7 т кисню (в середньому 10,5 т).

Посадку та проведення робіт в лісі здійснюють лісові господарства. Тому вартість кисню, який виробляється лісом за рік може бути оцінена річними витратами цих підприємств. В результаті обробки неофіційної інформації було отримано, що, наприклад, лісгосп, в який входить 63564 га площі під лісом, має річний бюджет в перерахунку 7,295 млн. \$. 3 них 5,143 млн. \$ є витрати на переробку лісних ресурсів, що є господарською діяльністю підприємства. Ця величина не відноситься до відновлення та підтримання стану лісу. Таким чином, собівартість виробництва кисню лісом може бути обрахована як

$$
\begin{gathered}
(7,295-5,143) \cdot 10^{6} /(63564 \cdot 10,5)= \\
=20,787 / 10,5=1,98 \$ / \mathrm{T}=45,54 \text { грн./T. }
\end{gathered}
$$

За рік 1 га лісу виробляє 10,5 т кисню, а собівартість 1 т кисню на рік, що виробляє ліс, складає 45,54 грн.

Таким чином, річні витрати будуть складатися 3 вартості витраченого палива, електроенергії на привід насосів, плати за викиди шкідливих речовин та плати за використання кисню.

Виходячи $з$ вищенаведеного, вираз (5) набуде наступний вигляд: 


$$
И_{\text {екол }}=\Pi_{\text {вик }}+\mathrm{M}_{\text {викидиСО2 }} \cdot\left(\mathrm{C}_{\text {пк }}+\mathrm{C}_{\text {кп }}\right)+\mathrm{M}_{\text {кисн }} \cdot \mathrm{C}_{\text {кисн }} \text {, }
$$

де $\Pi_{\text {вик }}-$ плата за викиди крім плати за викиди $\mathrm{CO}_{2}$, грн./т;

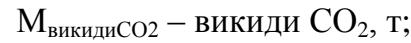

$\mathrm{C}_{\text {Пк }}$ - плата за викиди $\mathrm{CO}_{2}$ за Податковим кодексом України, $\mathrm{C}_{\Pi К}=0,26$ грн/т;

$\mathrm{C}_{\text {Кп }}$ - плата за викиди $\mathrm{CO}_{2}$ за Кіотським протоколом. Ціна на квоти на ринку коливається в районі 15-17 євро за 1 тонну $\mathrm{CO}_{2}$ [8]. В подальших розрахунках прийнято $\mathrm{C}_{\mathrm{K \Pi}}=20 \$ /$ т $\mathrm{CO}_{2}=500$ грн./т;

$\mathrm{M}_{\text {кисн }}$ - витрата кисню в установці при згорянні палива, т;

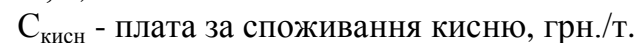

Звертаємо увагу, що пропонується враховувати плату за викиди $\mathrm{CO}_{2}$ як за Податковим кодексом України, так і за Кіотським протоколом. Не зважаючи на те, що зараз в результаті Паризької конференції умови виконання зобов'язань країн відносно плати за викиди пом'якшені, тільки економічні санкції можуть забезпечити стримування антропогенного впливу на довкілля.

Для прикладу реалізації запропонованої методики проведемо співставлення техніко-економічних показників для двох типів енергоустановок гарячого теплопостачання (ГВП): сонячної установки та котла на природному газі. Для співставлення зменшення техногенного навантаження за рахунок зниження використання природних ресурсів та викидів продуктів згорання визначимо витрати сонячних установок та котельних для ГВП та порівняємо їх.

\section{IV. ВИЗНАЧЕННЯ ПРИВЕДЕНИХ ВИТРАТ ДЛЯ КОТЕЛЬНОЇ УСТАНОВКИ НА ПРИРОДНОМУ ГАЗІ ДЛЯ ГАРЯЧОГО ВОДОПОСТАЧАННЯ}

За номінальну потужність споживача приймемо потужність сонячної енергоустановки (СЕУ), яку вона буде мати в літній день липня місяця. За липень на поверхню сонячного колектора (СК) з урахуванням хмарності потрапить 187 кВт·год/(м².місяць) [9]. 3 урахуванням оптичного ККД СК (72,8 \%[10]) кількість теплоти, яка буде передана споживачу, буде дорівнювати $187 \cdot 0,782=146,23$ кВт·год/м² ${ }^{2}$ Середньодобова потужність 146,23/(31-12) = 0,4 кВт. Вартість котла потужністю 0,4 кВт $=1341$ грн. $=53$ \$ [11].

При порівнянні експлуатаційних витрат $И_{3 п}$ та

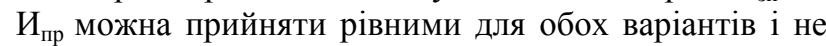
враховувати їх у розрахунках.

Експлуатаційні річні витрати:

$$
И=И_{\text {пал }}+И_{\mathrm{\kappa}}+И_{\text {екол }}=\mathrm{B}_{\text {річ }} \cdot Ц_{\text {пг }}+1,1 \cdot \mathrm{p}_{\mathrm{a}} \cdot \mathrm{K}+И_{\text {екол }}
$$

де $\mathrm{B}_{\text {річ }}$ - витрата природного газу за рік, м $^{3}$;

Ц $\bigsqcup_{\text {пг }}=7,18 г$ грн $/ \mathrm{m}^{3}[12]=0,287$ \$.

Отримана енергія за рік від сонця з одного квадратного метра $\mathrm{Q}_{\text {рік }}=1298,25$ кВт.год/м ${ }^{2}$ [9]. Отримана споживачем теплота буде дорівнювати: $1298,25=0,782=1015,23 \kappa$ кВтгод/м².
Ця енергія для порівнянності варіантів має бути отримана в першому випадку від котельної.

Необхідна кількість енергії від котла розраховується за формулою:

$$
\begin{aligned}
& \mathrm{Q}_{\text {кот }}=\mathrm{Q}_{\text {рік }} / \eta_{\text {кот }}= \\
& =1015,23 \cdot 3600 / 0,898=4069,96 \mathrm{MДж}
\end{aligned}
$$

де $\eta_{\text {кот }}$ ККД котла. Прийнято $\eta_{\text {кот }}=89,8 \%$ [11].

Відповідна кількість природного газу:

$$
\mathrm{B}_{\text {рік }}=\mathrm{Q}_{\text {кот }} / \mathrm{Q}_{\mathrm{H}}^{\mathrm{p}}=4069,96 / 35=116,28 \mathrm{M}^{3},
$$

$\mathrm{Q}_{\mathrm{H}}^{\mathrm{p}}=35$ МДж - теплота згоряння природного газу, прийнятого Шебелинського родовища [13].

При спалюванні природного газу утворюються $\mathrm{CO}_{2}, \mathrm{CO}, \mathrm{NO}_{\mathrm{x}}$. Згідно з Податковим кодексом України (ст. 243) здійснюється плата за викиди цих речовин за відповідними ставками $\quad \mathrm{C}_{\mathrm{CO} 2}=0,26$ грн. $/ \mathrm{T}$, $\mathrm{C}_{\mathrm{NOx}}=1553,79$ грн/т, $\mathrm{C}_{\mathrm{co}}=58,54$ грн./т [4].

Відповідно паспорту газового котла [11] при спалюванні $1 \mathrm{~m}^{3}$ природного газу утворюється $\mathrm{M}_{\mathrm{CO} 2}=0,001436 \mathrm{~T}, \mathrm{M}_{\mathrm{CO}}=1,04 \cdot 10^{-6} \mathrm{~T}, \mathrm{M}_{\mathrm{NOx}}=0,787 \cdot 10^{-6} \mathrm{~T}$.

При цьому витрачається $2 \mathrm{~m}^{3}$ кисню $(2 \cdot 32 \cdot 2 / 44,8=2,857$ кг $=0,002857 \mathrm{~T})$.

Таким чином, екологічний податок при спалюванні $1 \mathrm{M}^{3}$ природного газу складе:

$$
\begin{aligned}
& И_{\text {екол }}=\mathrm{M}_{\mathrm{CO} 2} \cdot \mathrm{C}_{\mathrm{CO} 2}+\mathrm{M}_{\mathrm{CO}} \cdot \mathrm{C}_{\mathrm{CO}}+ \\
& +\mathrm{M}_{\mathrm{NOx}} \cdot \mathrm{C}_{\mathrm{NOx}}+\mathrm{M}_{\mathrm{O} 2} \cdot \mathrm{C}_{\mathrm{O} 2}= \\
& =0,001436 \cdot(0,26+500)+0,787 \cdot 10^{-6} \cdot 1553,79+ \\
& +1,04 \cdot 10^{-6} \cdot 58,54+0,002857 \cdot 45,54=0,718+ \\
& +1,223 \cdot 10^{-3}+60,88 \cdot 10^{-6}+0,13=0,849 \text { грн. }
\end{aligned}
$$

Як видно з наведеного розрахунку, частка податку за викиди $\mathrm{CO}$ та $\mathrm{NO}_{x}$ така мала, що може у подальшому не враховуватися. Якщо враховувати тільки ставку податку за викиди $\mathrm{CO}_{2}$ відповідно Податковому кодексу України, то ця складова екологічного податку буде теж несуттєва.

При спалюванні 116,28 м³ плата за викиди:

$$
И_{\text {екол }}=0,849 \cdot 116,28=98,77 \text { грн. }
$$

Експлуатаційні річні витрати за виразом (8):

$И=116,28 \cdot 7,18+1,1 \cdot 0,07 \cdot 1341+98,77=1036$ грн.

Екологічний податок в сумі експлуатаційних витрат має частку 9,5\%.

Розрахункові приведені витрати в котельній установці:

$$
\text { Зк }=0,12 \cdot 1341+1036=1196,9 \text { грн. }
$$

Якщо розрахувати екологічну складову за сьогоднішньою методикою, то при згорянні $1 \mathrm{~m}^{3}$ природного газу вона буде дорівнювати 0,001657 грн., а Иекол $=$ $0,001657 \cdot 116,28=0,193$ грн. Приведені витрати у цьому випадку:

$$
\text { Зк }=0,12 \cdot 1341+937,49=1098,41 \text { грн. }
$$

Таким чином, пропозиції враховувати плату за викиди $\mathrm{CO}_{2}$ додатково за Кіотським протоколом та враховувати плату за використання кисню підвищують екологічну складову у 2651 раз, а приведені витрати на $8,97 \%$. 


\section{V. ВИЗНАЧЕННЯ ПРИВЕДЕНИХ ВИТРАТ ДЛЯ СОНЯЧНОЇ УСТАНОВКИ}

Капітальні витрати - це вартість сонячної установки 3 колектором площею $1 \mathrm{~m}^{2}$. Для аналізу прийнято використання плоских СК марки Altek AFL-AL [10]. Вартість колектора становить $368 \$=9200$ грн. При корисній площі колектора 1,8 м $^{2}$ питома вартість колектора складе Кск $=9200 / 1,8=$ $=5111,1$ грн./ $\mathrm{m}^{2}$. Оскільки сонячна установка включає ще багато інших технологічних елементів, прийнято Ксу $=$ Кск $2=5111,1 \cdot 2=10222,2$ грн.

Витрати на паливо та екологічний податок відсутні. Таким чином, експлуатаційні річні витрати:

$$
И=1,1 \cdot \mathrm{p}_{\mathrm{a}} \cdot \mathrm{K}=1,1 \cdot 0,07 \cdot 10222,2=787,1 \text { грн. }
$$

Витрати на привід насосів в обох установках незначні. Таким чином, приведені витрати в сонячній установці:

$$
\text { Зсу }=0,12 \cdot 10222,2+787,1=2013,77 \text { грн./рік. }
$$

Отже, витрати у разі застосування сонячних установок та витрати для котельної на природному газі відрізняються у 1,68 разів. Якщо знехтувати витратами на поточних ремонт, що має місце у приватних енергоустановках малої потужності (наприклад, приватні котеджі), то річна економія від використання СУ складе

$$
\begin{aligned}
\mathrm{E}_{\text {річ }}=\mathrm{B}_{\text {річ }} \cdot Ц_{\text {пг }}+U_{\text {екол }}=116,28 \cdot 7,18+98,77= \\
=932,74 \text { грн. }
\end{aligned}
$$

Тоді термін окупності використання СУ визначиться як:

$$
\mathrm{T}_{\text {ок }}=\Delta \mathrm{K} / \mathrm{E}_{\mathrm{piч}}=(10222,2-1341) / 932,74=9,52 \text { роки. }
$$

Цей термін незначно перевищує нормативне значення у 7 років і може бути прийнятним.

\section{ВИСНОВКИ}

Запропоновано удосконалену методику технікоекономічного співставлення енергетичних установок, яка при розрахунку екологічної складової приведених витрат враховує плату за викиди $\mathrm{CO}_{2}$ як за Податковим кодексом України, так і за Кіотським протоколом.

Запропоновано при співставленні різних енергоустановок при розрахунку екологічної складової приведених витрат враховувати плату за використання кисню. Запропоновано методику визначення ставки податку за використання кисню.

\section{ЛIТЕРАТУРА}

1. Методичні вказівки з техніко-економічного обгрунтування інвестиційних проектів електричних станцій для студентів спеціальності «Теплові електричні станції», «Атомні електричні станції»/Уклад.: Є. Г. Скловська, К. Г. Тодорович. - К.: ІВЦ «Видавництво «Політехніка», 2002. - 24 с.

2. Макарова, Н. С. Економіка природокористування: Навчальний посібник / Н. С. Макарова. - К.: Центр учбової літератури, 2007. - 322 с.

3. Мельник, С. В. Економіка природокористування: навч. посіб. / С. В. Мельник. - О.: Наука і техніка, 2012. -224 c.

4. Податковий кодекс України [Електронний ресурс] / Режим доступу: http:// search.ligazakon.ua/l_doc2.nsf/ link1/T102856.html/ - Дата звернення 09.01.2016.

5. Верхивкер, Г. П, Теплоснабжение от атомных электростанций / Г. П. Верхивкер, В.П. Кравченко, В. А. Дубковский. - Одесса: ВМВ, 2010. - 410 с.

6. Зыков, А. М. Технология СНКВ и перспективы ее широкого применения в теплоэнергетике /А. М. Зыков, И. В. Афанасьев, С. И. Аничков и др. // Сборник научных трудов «Проблемы теплоэнергетики. Вып. 2». - Саратов: СГТУ, 2012. - С. 19-26.

7. Фоменко, Н. В. Рекреаційні ресурси та курортологія. - К.: Центр навчальної літератури, 2007. - 312 с.

8. Лесков С. Киотский протокол включился [Электронный ресурс] / Режим доступа: http://www.ecomir.ru/ecology/action/75. - Дата звернення 20.12.2013.

9. СНиП 23-01-99* Строительная климатология. - М., 2003. [Электронный ресурс] / Режим доступу: http://gostrf.com/norma_data/7/7001/. - Дата звернення 10.01.2016.

10. Плоский солнечный коллектор AFL-AL. Каталог товаров [Электронный ресурс] / Режим доступа: http://powersolar.com.ua/Плоский-солнечный-коллектop-Altek-AFL-AL.html. - Дата звернення 10.01.2016. 11. Газовый котел Alpha CB-24-TF [Электронный ресурс] / Режим доступу: /http://termoklimat.com.ua/ kotly-gazovye/alpha-cb-24-tf.html. - Дата звернення 10.01.2016.

12. Постановление НКРЭ от 03.03.2015 № 583 «Об утверждении розничных цен на природный газ, который используется для потребностей населения»: [Электронный ресурс] / Режим доступу: http://www.nerc.gov.ua/?id=14329. - Дата звернення 03.03.2015.

13. Теплотехнический справочник. Т.1/ Под ред. В. Н. Юренева, П. Д. Лебедева. - М.: Энергия, 1975. $744 \mathrm{c}$.

Отримана в редакції 04.02.2016, прийнята до друку 03.03.2016 


\section{Kravchenko, Ie. Kravchenko}

Odessa National Polytechnic University, 1 Shevchenko av., Odessa, 65044, Ukraine

Comparison of power plants comes true on the annual brought expenses over, that must take into account an ecological constituent. It is offered at the calculation of paying for extras smoke gas rate of tax for the carbon dioxide extras to expect as a sum of rate on the internal revenue code of Ukraine and rate on Kyoto protocol. One of advantages of sunny, wind and atomic energy is absence of the oxygen use. It is suggested at comparison of different power plants to take into account paying for the oxygen consumption. Methodology of determination of tax rate for the consumption of oxygen is offered. It is based on determination of expenses forestry for the care of the forest with the known area and type of trees. It allows defining the annual amount of oxygen producible this forest. As an example the uses of the offered methodology a calculation the brought expenses over for the options of hot water-supply with boiler on natural gas and sunny collectors is presented. It is got as a result of calculations, that the brought expenses over in a boiler room less expenses in the sunny plant in 1,68. Suggestions to take into account paying for the extras of CO2 additionally according to Kyoto protocol and to take into account paying for the use of oxygen promote an ecological constituent in 2651 times, and the brought expenses over on 8,97\%.

Keywords: Annual brought expenses over; Ecological constituent of operating expenses; Paying for the use of oxygen.

\section{REFERENCES}

1. Metodychni vkazivky z tekhniko-ekonomichnogo obgruntuvannya investyciynyh proektiv elektrychnyh stanciy dlya studentiv specialnosti "Teplovi elektrychni stancii", "Atomni elektrychni stancii" / Compilers: Ie.G. Sklovska, K.G. Todorovich. - K.: IVC "Vydavnyctvo «Polytechnic», 2002. - $24 \mathrm{c}$.

2. Makarova, N.S. Ekonomika pryrodokorystuvannja: Navchal'nyj posibnyk. - Kiev: Centr uchbovoi lieratury, 2007. - 322 p.

3. Melnik, S. V., Ekonomika pryrodokorystuvannja: Navchal'nyj posibnyk. - Odessa: Science and Technology, 2012. - 224 p.

4. Podatkovyj kodex Ukrainy. Web. 09 January 2016 <http:// search.ligazakon.ua/1_doc2.nsf/link1/T102856.html $>$.

5. Verkhivker G., Kravchenko V., Dubkovsky, V. (2010). Teplosnabgenie ot atomnyh elektro srancij. Odessa: BMV, - 410 p.

6. Zykov, A., Afanasyev, S. Anichkov, S. i dr. Technologiya SNCV i perspektivy ego shirokogo primeneniya v teploenergetike // Sbornik nauchnyh trudov "Problemy teploenergetiki, Vyp.2». - Saratov: Saratovsky gosudarstvenny universitet, 2012. - P. $19-26$.
7. Fomenko, N. Recreacijni Resurcy I kurortologiya. K.: Centr navchal'noj literatury, 2007. - 312 p.

8. Leskov, S. Kyotskiy protocol vklyuchilsya. Web. 12 December 2013. <http://www.eco-mir.ru/ecology/action/ 75>.

9. SNIP 23-01-99 * Stroitel'naya klivatologiya - M., 2003. Web. 10 January 2016. $<$ http://<gostrf.com/norma_data/7/7001>.

10. Ploskiy solnechnyj collector AFL-AL. Catalog. Web. 10 January 2016. <http://powersolar.com.ua/Плоскийсолнечный-коллектор-Altek-AFL-AL.html>.

11. Gasovyj kotjolr Alpha CB-24-TF Web. 10 January 2016. </http://termoklimat.com.ua/kotly-gazovye/alphacb-24-tf.html>.

12. Postanovlenie ot 03.03.2015 № 583 "Ob utvergdenii roznichnyh cen na prirodnyj gas, kotoryj ispol'zuetsya dlya potrednostej naseleniya". Web. 03 March 2015. </http://www.nerc.gov.ua/?id=14329>.

13. Teplotechnicheskij spravochnik. Tom.1 / Red. V. Yurenev, P. Lebedev. - M.: Energiya, 1975. - 744 p.

Received 04 February 2016 Approved 03 March 2016 Available in Internet 29 April 2016- 